Article

\title{
Wind-Tunnel Studies on Sand Sedimentation around Wind-Break Walls of Lanxin High-Speed Railway II and Its Prevention
}

\author{
Hongchao Dun ${ }^{1,2,+, \ddagger}\left(\mathbb{D}\right.$, Guowei Xin ${ }^{1,2}$, Ning Huang ${ }^{1,3,4}$, Guangtian Shi ${ }^{3,4}$ and Jie Zhang ${ }^{1,2, *, \ddagger}$ \\ 1 Key Laboratory of Mechanics on Disaster and Environment in Western China, Lanzhou University, \\ Lanzhou 730000, China; dunhc@lzu.edu.cn (H.D.); xingw17@lzu.edu.cn (G.X.); huangn@lzu.edu.cn (N.H.) \\ 2 College of Civil Engineering and Mechanics, Lanzhou University, Lanzhou 730000, China \\ 3 Key Laboratory of Service Environment and Intelligent Operation and Maintenance of Rail Transit, \\ Lanzhou Jiaotong University, Lanzhou 730070, China; zxaazxy@163.com \\ 4 School of Mechanical Engineering, Lanzhou Jiaotong University, Lanzhou 730070, China \\ * Correspondence: zhang-j@lzu.edu.cn \\ + Current address: No. 222 South Tianshui Road, Lanzhou 730000, China. \\ $\ddagger \quad$ These authors contributed equally to this work.
}

Citation: Dun, H.C.; Xin, G.W.; Huang, N.; Shi, G.T.; Zhang, J. Wind-Tunnel Studies on Sand Sedimentation around Wind-Break Walls of Lanxin High-Speed Railway II and Its Prevention. Appl. Sci. 2021, 11, 5989. https://doi.org/10.3390/ app11135989

Academic Editor: Itzhak Katra

Received: 19 April 2021

Accepted: 17 June 2021

Published: 27 June 2021

Publisher's Note: MDPI stays neutral with regard to jurisdictional claims in published maps and institutional affiliations.

Copyright: (c) 2021 by the authors. Licensee MDPI, Basel, Switzerland. This article is an open access article distributed under the terms and conditions of the Creative Commons Attribution (CC BY) license (https:/ / creativecommons.org/licenses/by/ $4.0 /)$.

\begin{abstract}
Wind-break walls along Lanxin High-Speed Railway II were studied and approved as effective measures to reduce strong wind damage to the high-speed trains. The results show that sand sedimentation on the leeward sides of wind-break walls along the railway within Gobi Desert could significantly threaten the operation safety of running trains. Different from the current sand sedimentation prevention measures without adequate consideration of the deposition process of airborne sand particles, this study revealed the mechanism of sand sedimentation on the leeward sides of three wind-break walls within different terrains. A series of wind-tunnel experiments were carried out to measure the horizontal velocity, number density, transport flux, and deposition rate of sand particles, and it was found that the horizontal speed of sand particles was first increased and then decreased on the railway track, and the peak speed over the concave subgrade was much smaller than those over convex and flat subgrades. The number density and horizontal sand flux were largest over the concave subgrade, and were the smallest over the convex subgrade. The sand particle deposition rate and distribution were also the largest within the concave subgrade, and some measures were also proposed to prevent sand sedimentation on the leeward sides of wind-break walls.
\end{abstract}

Keywords: sand particle; wind-break wall; terrain; railway; wind-tunnel experiment

\section{Introduction}

Within China's extensive high-speed railway system, the Lanxin High-Speed Railway II from Lanzhou to Xinjiang in western China is the first known high-speed railway crossing a long wind area (more than $462.4 \mathrm{~km}$ ) with extremely high wind speeds [1-3]. Because there are 208 days every year with wind speeds of higher than $20 \mathrm{~m} / \mathrm{s}$ and the highest wind speed is over $60 \mathrm{~m} / \mathrm{s}[4,5]$, strong wind will cause train overturning, vehicle runaway, window glass shattering, power supplying equipments damage, etc., which further leads to the loss of safety in train operation, maintenance, and transportation [6-9].

In order to prevent damage to trains from strong winds, many wind-proof constructions, such as subgrade wind-break walls, bridge windscreens, and wind-proof tunnels, were built along Lanxin High-Speed Railway II [2]. Because wind-break walls are the most common wind-proof structure with low cost and simple construction [10], many wind-break walls with a height of 2.0 to $4.3 \mathrm{~m}$ have been built in wind zones to significantly reduce both the wind speed and the overturning force to vehicles. 
However, as shown in Figure 1c,d, wind-break walls can easily cause sand sedimentation around railway tracks, which threatens the safe operation of high-speed trains. For example, in the Gobi Desert with dry loose soil and abundant surface particles [11-13], strong wind is usually accompanied by sand and dust flow, which will be deposited on the railway track [14]. Therefore, the high-speed train can only cross Lanxin High-Speed Railway II during the daytime in order to clear the deposited sand during the night [15]. The mechanism of sand sedimentation on the leeward sides of wind-break walls has recently been given serious attention. Cheng analyzed the characteristics of sand accumulation of three different types of wind-break walls by three-dimensional numerical simulations and wind-tunnel experiments and found that the wind-break wall with bottom-openings achieved improved sand dredging at high wind speeds [16]. Huang explored the characteristics of wind-blown sand flow around the wind-break wall and the causes of sand accumulation by setting up a turbulent flow-sand particle-terrain coupling model using the Lagrangian particle-tracing model and found that sand particles will be blown up and rolled back to the subgrade under the effect of vertical wind velocity and reflux [15]. Similar phenomena had been found in highways and civil constructions in arid and semi-arid regions [17-19].
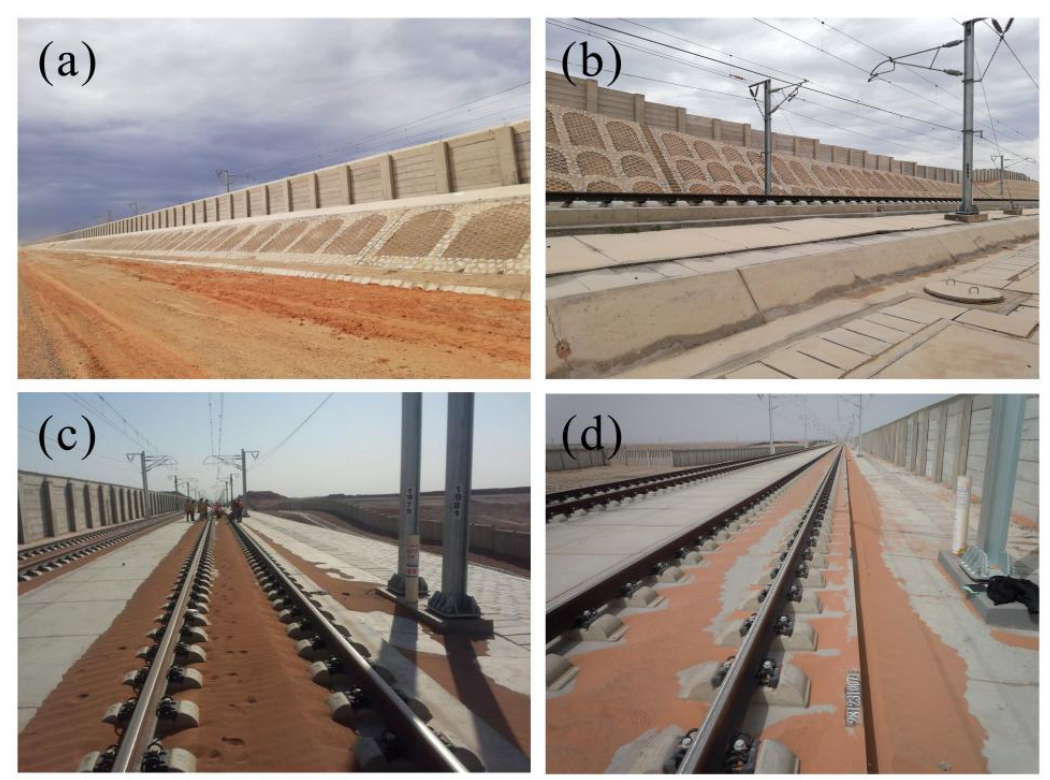

Figure 1. (a) Convex subgrade and (b-d) concave subgrades. Note: The wind-break wall is different from the sand fence (see Appendix A).

Up to present, the sand accumulation around the wind-break wall is mainly cleared manually with very low efficiency. The current measures to prevent sand deposition are practiced without adequate consideration of the deposition process of airborne sand particles and topographic factors. However, the varied terrain along the Lanxin High-Speed Railway II includes convex, flat, and concave topography as shown in Figure 1a (convex) and Figure $1 \mathrm{~b}$ (concave). Therefore, studies and optimization on the original wind-break wall structures within different terrains to reduce sand sedimentation are essentially urgent.

In this study, according to the sand sedimentation caused by wind-break walls and different terrain and railway track characteristics of Lanxin High-Speed Railway II, three models of wind-break walls were established and examined through the wind-tunnel experiment with the reproduced movement process of windblown sand. In the windtunnel experiments, the particle image velocimetry (PIV) system was used to collect sand movement images on the leeward side, and PTV technology was employed to obtain the sand particle movement laws. The changes in wind speed, sand particle speed, sand particle number density, sand transport flux, and sand particle deposition rate on the railway track as well as the flow field around wind-break walls (numerical simulation) 
were analyzed systematically to understand the sand sedimentation around wind-break walls under different terrain, which will provide an excellent reference for train-running safety in strong wind areas with sand damage.

\section{Experimental Setup and Methods}

\subsection{Wind-Tunnel Experiment}

All wind-tunnel experiments were carried out in a blow-down wind tunnel at Lanzhou University. The wind tunnel was $55 \mathrm{~m}$ long and included a powerful fan system, a rectification section, a working section, and a diffuser. The length of its working section was about $22 \mathrm{~m}$, and the cross-sectional area of its working section was $1.3 \mathrm{~m}$ (width) $\times 1.45 \mathrm{~m}$ (height). The wind tunnel was controlled by a computer, and the wind speed could be adjusted between 3 and $40 \mathrm{~m} / \mathrm{s}$ as the normal wind speed in nature [20,21].

As shown in Figure 2, in the experimental setup, roughness elements were in the front of the work section to generate a turbulent boundary layer with a thickness of 0.3 to $0.4 \mathrm{~m}$. A monitoring Pitot tube was used to measure the inlet wind speed. A measuring Pitot tube was fixed to a frame to measure wind speeds around three models at the 17 points of 2.0, $4.0,7.0,10.0,15.0,20.0,30.0$, and $45.0 \mathrm{~cm}$ above the surface. The obtained data were used to analyze the spatial and temporal distributions of the wind speed. Particle image velocimetry (PIV) was used to measure the speed of sand particle on the railway track.

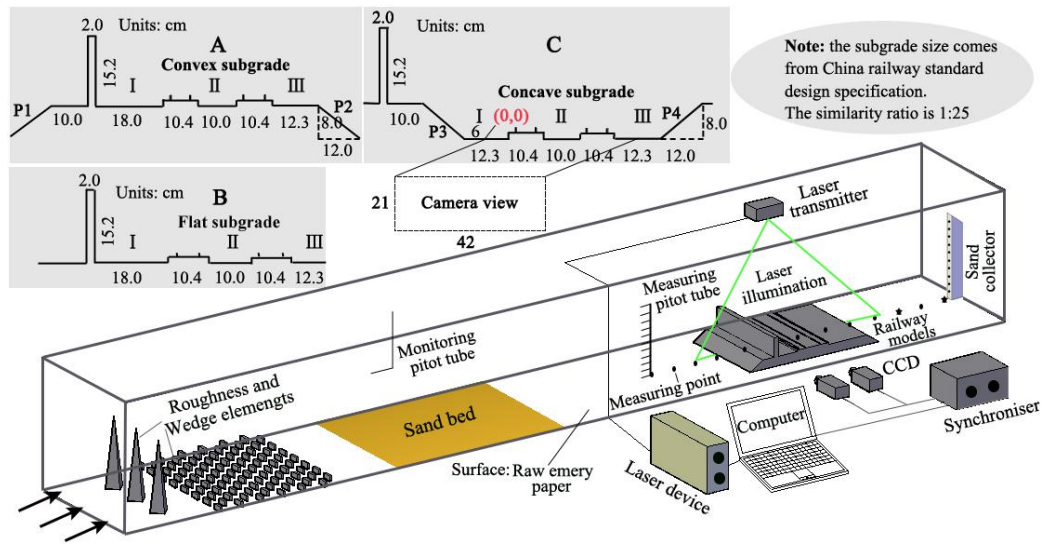

Figure 2. Configuration of the wind-tunnel experiment, in which downstream of the roughnesselement is the test surface, the model $(100 \mathrm{~cm}$ wide and $100 \mathrm{~cm}$ long) is $9 \mathrm{~m}$ away from the sand bed, the sand bed ( $130 \mathrm{~cm}$ wide, $300 \mathrm{~cm}$ long and $5 \mathrm{~cm}$ deep) is placed after the roughness elements, A is the convex wind-break wall with P1 and P2 as its two slopes, B is the flat wind-break wall, C is the concave wind-break wall with P3 and P4 as its two slopes, and the coordinate origin $(0,0)$ of the camera view is as shown in the figure. Turbulence intensity is 0.05 .

The PIV system had a laser and transmitter, a high-resolution charge coupled device (CCD) camera, a synchronizer, and a computer with an image acquisition card. The laser emitter was on the top of the wind tunnel, and its laser beam coincided with the axis section of the model. The frequency of the laser was $5 \mathrm{~Hz}$ and the pulse energy was $120 \mathrm{~mJ}$. The high-resolution CCD camera and the pulsed laser were synchronized with a pulse delay generator. Two CCD cameras with a pixel resolution of $2048 \times 2048$ and a sampling rate of 500 frames per second were at the side of the wind tunnel. The field of these two cameras was about $21 \mathrm{~cm}$ (height) $\times 42 \mathrm{~cm}$ (width). The images of particle tracking velocimetry (PTV) were processed to obtain the sand particle velocity and number density.

Although there are many similarity requirements in wind-tunnel experiments, such as geometric, motion, dynamic, and thermodynamic similarity [22,23], with sand flow it is difficult to perfectly simulate the shrinkage ratio of the model size, boundary layer size, and particle size in the real environment. Therefore, in this study, some compromises must be adopted [24]. Only the geometric similarity of the model, the motion similarity and dynamic similarity of the wind field, and the corresponding wind-tunnel results were 
mainly used in the mechanical studies as a key problem to be solved in current wind-sand physics $[23,25,26]$.

\subsection{Numerical Simulation}

Due to the complicated structure of the flow field in the leeward side of wind-break walls, it is difficult to obtain flow information accurately with a Pitot tube as the only onedimensional and unidirectional speed measuring device. Therefore, numerical simulation on computational fluid dynamics (CFD) was used to study the wind field information under the corresponding conditions of the wind-tunnel experiments (Figure 3). Meanwhile, the wind speed comparison between the wind-tunnel experiment and the numerical simulation was used to verify the reliability of the numerical simulation. Results show that the three-dimensional channel size of the numerical simulation was consistent with the working section of the wind tunnel. The wind speed profiles of wind-tunnel experiments were collected at the inlet with the velocity-inlet as the inlet boundary condition, the outflow as the outlet boundary, and the walls as other boundaries [27-29].

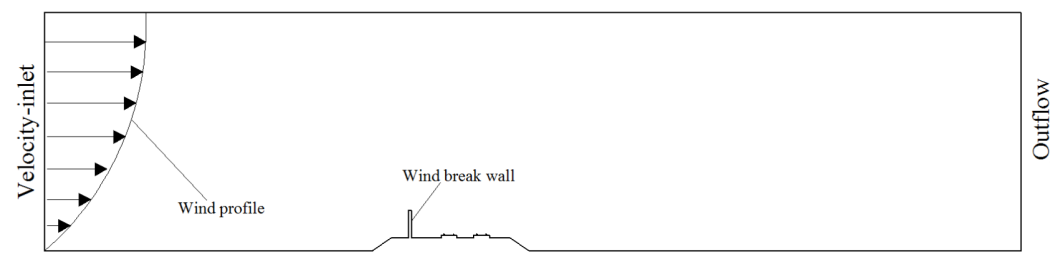

Figure 3. Configuration of numerical simulation. The dimensional channel size of the numerical simulation was consistent with the working section of the wind tunnel.

\subsection{PTV Image Processing}

The PTV is a non-contact, transient whole-field particle velocity measuring method to identify the movement of sparse particles [30,31]. Figure 4 shows the post-processing process of particle motion caught by the PIV system [32]. Within the square region $(0.01 \mathrm{~m} \times 0.01 \mathrm{~m})$ of the PIV image, the number of sand particles was counted to calculate the velocity and number density of sand particles according to the following Equations (1) and (2).

$$
\begin{gathered}
v_{i}=\frac{\min \left(\sqrt{\left(x_{2 i}-x_{1 i}\right)^{2}+\left(y_{2 i}-y_{1 i}\right)^{2}}\right)}{\Delta t}, \\
\frac{S_{2 i}}{S_{1 i}} \leq 3
\end{gathered}
$$

where $\min \left(\sqrt{\left(x_{2 i}-x_{1 i}\right)^{2}+\left(y_{2 i}-y_{1 i}\right)^{2}}\right)$ represents the minimum distance between all particles in the second frame and the $i$ th particle in the first frame, $v_{i}$ represents the velocity of the $i$ th particle in the first frame image, $\Delta t$ represents the time interval between two frames, $S_{1 i}$ is the sand particle area in the first frame, and $S_{2 i}$ is the sand particle area in the second frame.

The sand particle number density $N_{z}$, horizontal particle velocity $v_{x}$, and horizontal sand flux $Q_{x}$ around the three wind-break walls were calculated out from the obtained images according to the following Equations (3)-(5) [33].

$$
\begin{gathered}
N_{z}=\frac{n_{z}}{\Delta x \Delta y \Delta z}, \\
v_{x}=\frac{L_{x}}{\Delta t^{\prime}} \\
Q_{x}=\frac{\pi}{6} \rho d^{3} N_{z} v_{x},
\end{gathered}
$$


where $L_{x}$ is the moving distance of a particle along $x$-direction; $\Delta t$ is the time interval of $110 \mu \mathrm{s}\left(u_{*}=0.9701 \mathrm{~m} / \mathrm{s}\right), 170 \mu \mathrm{s}\left(u_{*}=0.6595 \mathrm{~m} / \mathrm{s}\right)$ and $250 \mu \mathrm{s}\left(u_{*}=0.4756 \mathrm{~m} / \mathrm{s}\right)$ between two laser pulses; $n_{z}$ is the total number of sand particles in a cuboid; $\Delta x, \Delta y$, and $\Delta z$ are the three sides of the cuboid, in which both $\Delta x$ and $\Delta y$ are $0.01 \mathrm{~m}$, and $\Delta z(1 \mathrm{~mm})$ is the depth of the laser; $\mathrm{d}(\sim 160 \mu \mathrm{m})$ is the average sand particle diameter in the railway track; and $\rho$ is the particle density $\left(2650 \mathrm{~kg} \cdot \mathrm{m}^{-3}\right)$.

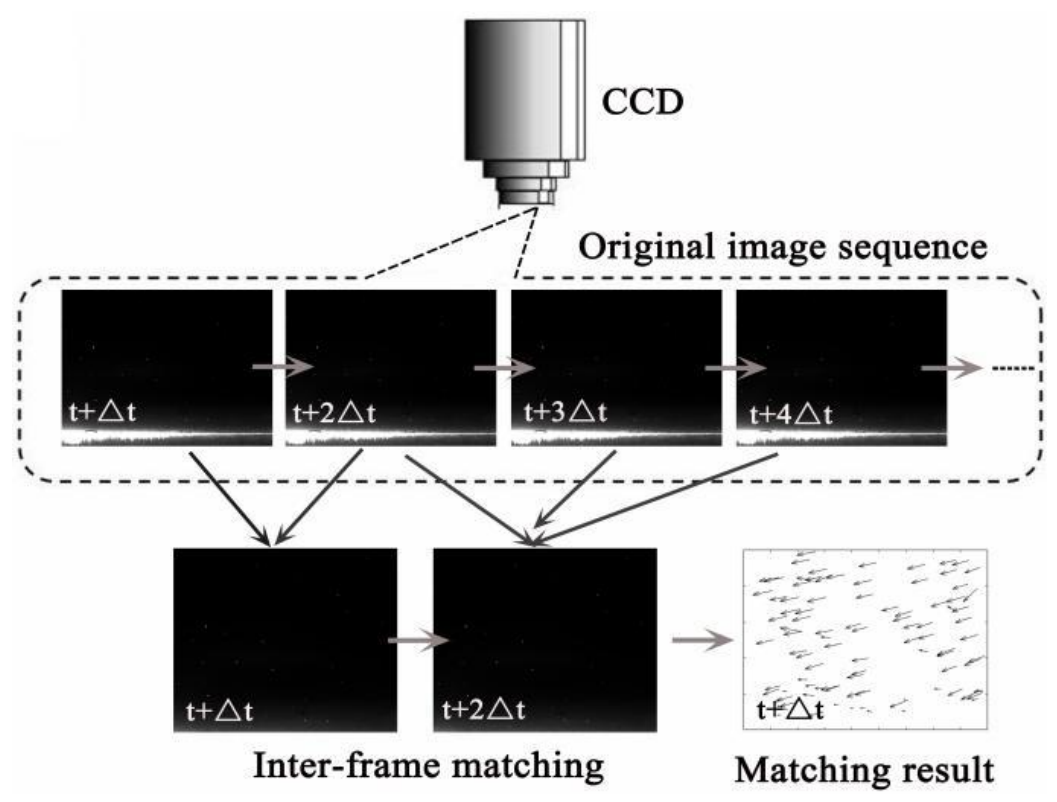

Figure 4. The post-processing procedure.

After the sedimentation of sand particles within I, II, and III on the railway track was weighed, the sand deposition rate was determined according to the following Equation (6).

$$
\lambda=\frac{m_{z} i}{t \cdot s_{i}}
$$

where $\lambda$ is the deposition rate, $m$ is the total sedimentation of sand particles, $t$ is the experimental time, and $s_{i}$ is the area of I, II, and III.

\section{Results}

\subsection{Wind Profiles and Size Distribution of Sand Particles}

Figure 5 shows the size distribution of sand particles in the wind-tunnel experiment. The sand particle size followed a normal distribution, and the mean particle size was about $220 \mu \mathrm{m}$.

Figure 6 shows the horizontal wind speeds at different heights over the surface without the Pitot tube. The fitting parameters of the wind profiles, such as the friction velocity $\left(u_{*}\right)$ and the roughness length $\left(z_{0}\right)$, are shown in the label of Figure 6. The results show that the wind profiles perfectly obey a logarithmic distribution. 


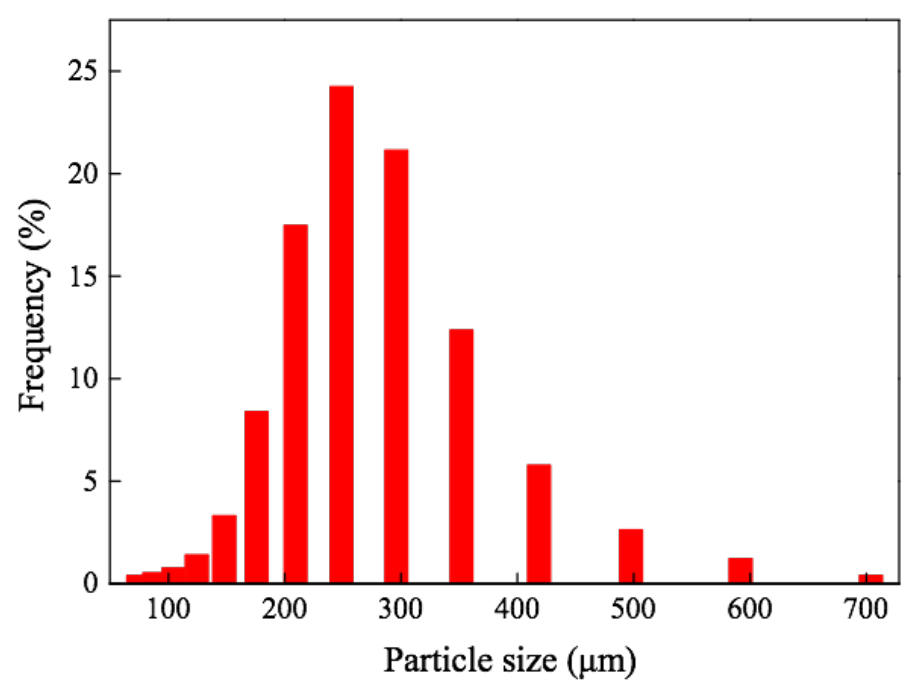

Figure 5. The size distribution of sand in the sand bed.

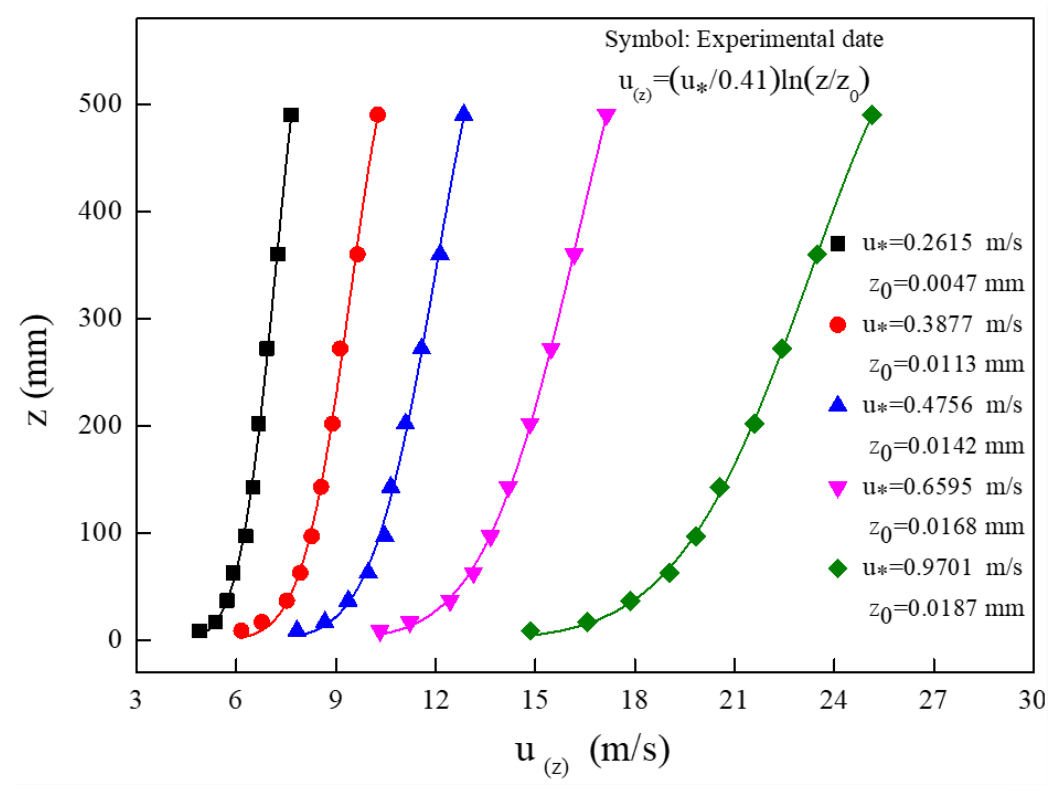

Figure 6. Wind profiles with experimental data and the profile curves fitted to the logarithmical law.

\subsection{Wind Field around Three Wind-Break Walls}

The horizontal wind speeds in different terrains around three wind-break walls measured with the Pitot tube are shown with black, blue, and red lines in Figure 7. The windbreak wall is located at the zero point of the x-axis, and the measuring height in Figure 7a is $15 \mathrm{~cm}$, and $30 \mathrm{~cm}$ in Figure $7 \mathrm{~b}$. A wind speed of $u_{*}=0.9701 \mathrm{~m} / \mathrm{s}$ was utilized as an example to analyze the wind speed variation. As shown in Figure 7, the horizontal wind speeds in three terrains were decreased then increased with $x$ distance. The horizontal wind speed reached its peak on the leeward side and was gradually increased with $x$ distance, and the peak of the concave subgrade was much lower than that of the convex and flat subgrade. Meanwhile, as shown in Figure $7 \mathrm{a}$, the minimum speed of convex, flat, and concave subgrade on the leeward side was $2.73,2.23$, and $0 \mathrm{~m} / \mathrm{s}$, respectively. Although, according to numerical simulations, the speed on the leeward side of the concave subgrade should be negative at the height of $15 \mathrm{~cm}$, the speeds of convex and flat were both positive because the Pitot tube measurements were all positive and could not be negative in wind-tunnel experiments. Therefore, the numerical simulation was applied to supplement the complete flow field information around wind-break walls. 

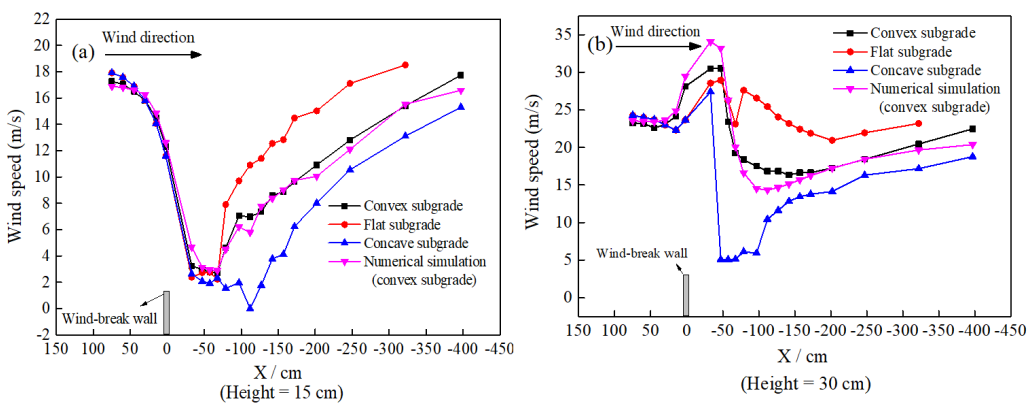

Figure 7. Wind speeds around three wind-break walls $\left(u_{*}=0.9701 \mathrm{~m} / \mathrm{s}\right)$, and the measuring heights are: (a) $15 \mathrm{~cm}$ and (b) $30 \mathrm{~cm}$.

In order to verify the reliability of numerical simulations in this study, numerical wind speeds of the convex wind-break wall at different heights were compared with those from the wind-tunnel experiments, as shown with the pink line in Figure 7. The results show that all simulation results are basically consistent with those collected in the wind tunnel.

The major stream-wise wind fields around these three wind-break walls under different terrains are shown in Figure 8a-c (symmetry plane in $x-z$ direction). The results show that the acceleration and vortex zone appear successively, and a large vortex zone was formed on the leeward side of the wind-break walls, which is consistent with reported results [28]. As shown in Figure 8, when the wind rolled back to the track under the action of the vortex zone, the wind speed was reduced due to the obstruction of convex slope P2. However, concave slope P4 could increase the wind speed towards the railway track, and slope P3 could slow down the wind speed that carried away a lot of sand particles, indicating that a large number of sand particles would be deposited in the concave subgrade. The wind speed on the leeward side of the flat subgrade was between those of concave and convex terrains.
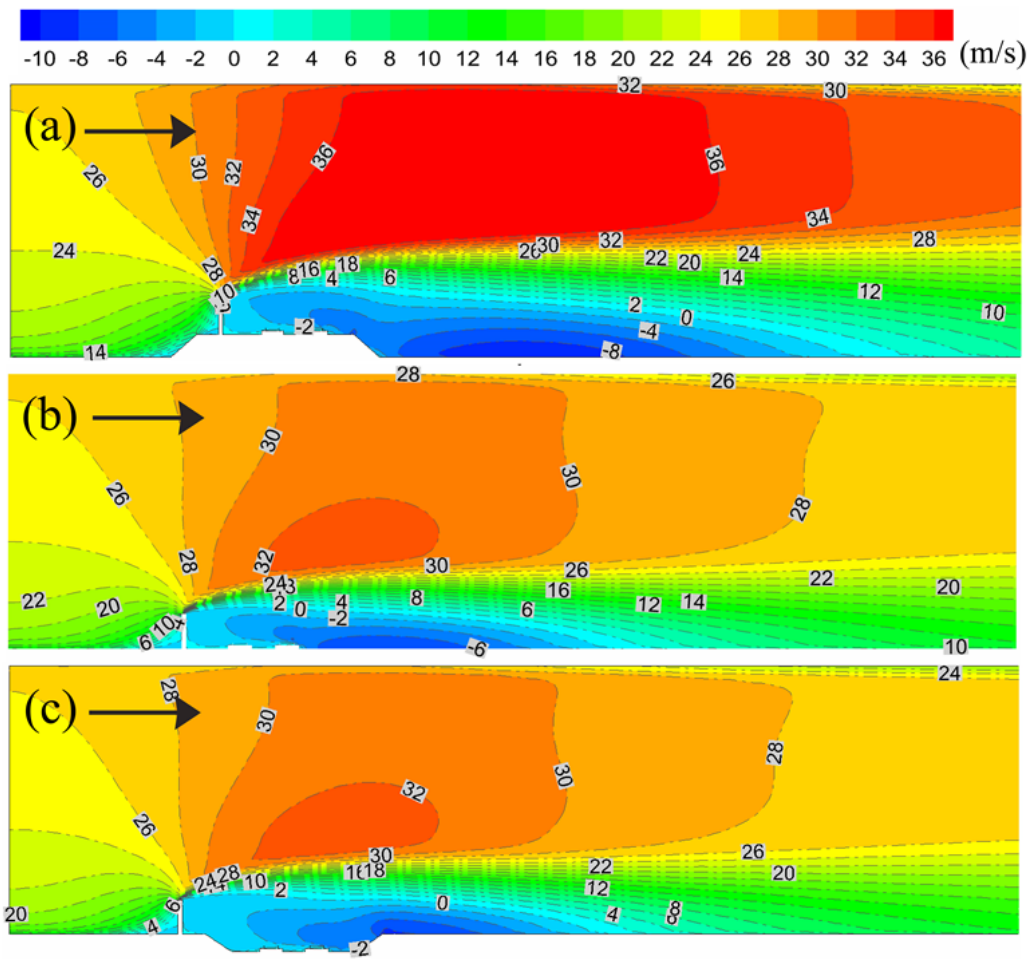

Figure 8. Wind fields around wind-break walls $\left(u_{*}=0.9701 \mathrm{~m} / \mathrm{s}\right)$ : (a) convex subgrade, (b) flat subgrade, and (c) concave subgrade. 


\subsection{Horizontal Speeds, Number Density, and Fluxes of Sand Particles}

Figure 9 shows the changes in horizontal speeds of sand particles along the $x$-direction on the leeward side with different terrains when the incoming wind speed $u_{*}$ is $0.9701 \mathrm{~m} / \mathrm{s}$. The results show that the horizontal speeds of sand particles were increased first and then decreased negatively with $\mathrm{x}$ distance on the leeward side. The speeds reached their peaks within $0.4-0.5 \mathrm{~m}$ and were gradually decreased after $0.5 \mathrm{~m}$. The increase of horizontal speed of sand particles was the largest in the case of $C$, which were $-11.2 \mathrm{~m} / \mathrm{s}$ at $0.05 \mathrm{~m}$ and $-10.2 \mathrm{~m} / \mathrm{s}$ at $0.1 \mathrm{~m}$, respectively. Compared with that in case of $\mathrm{C}$, in the cases of $\mathrm{A}$ and $\mathrm{B}$ the horizontal speeds of sand particles were respectively reduced by $33 \%$ and $13 \%$ at $0.05 \mathrm{~m}$, and by $22 \%$ and $8 \%$ at $0.10 \mathrm{~m}$, because the horizontal speeds of sand particles within $0.4-0.5 \mathrm{~m}$ were affected by the vortex zone, and the negative feedback effect on sand particles was significant. Moreover, the horizontal speeds of sand particles were reduced due to the obstruction of convex slope P2 and increased due to the concave slope P4. Therefore, the horizontal speed of sand particles in the case of $\mathrm{C}$ was higher than that in $\mathrm{A}$ or $\mathrm{B}$.
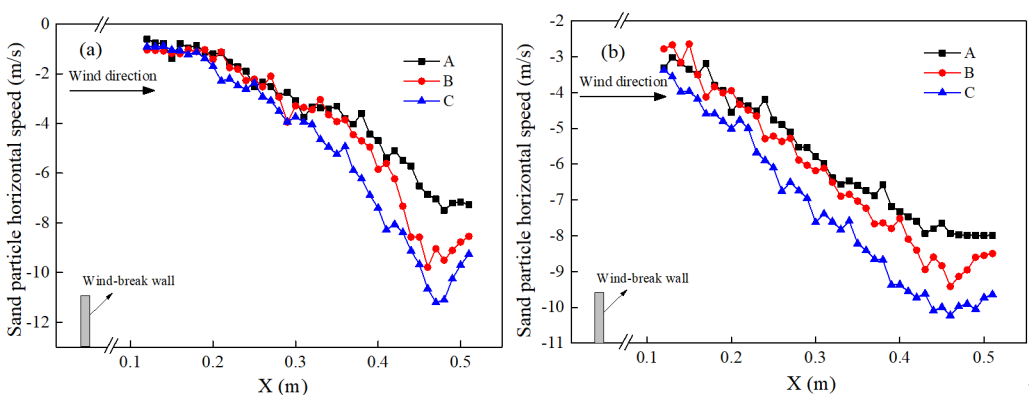

Figure 9. Sand particle's horizontal speed along the leeward side $\left(u_{*}=0.9701 \mathrm{~m} / \mathrm{s}\right) .(\mathbf{a}) \mathrm{H}=0.05 \mathrm{~m}$ (above the track). (b) $\mathrm{H}=0.10 \mathrm{~m}$ (above the track).

Figure 10 shows the change in sand particle number density along the $x$-direction at different heights. The results show that the sand particle number density of the three wind-break walls was first increased and then decreased. The sand particle number density of case $\mathrm{C}$ was the highest. Compared with that in case $\mathrm{C}$, the peaks of case $\mathrm{B}$ were decreased by $21 \%$ and $47 \%$ at heights 0.05 and $0.10 \mathrm{~m}$, respectively; and those of case A were decreased by $50 \%$ and $65 \%$ at heights 0.05 and $0.10 \mathrm{~m}$, respectively. With the increase in height, the sand particle number density was gradually decreased and the amplitude of these changes was increased, indicating that the sand particle concentration was larger at a lower height and smaller at a higher location. Additionally, the sand particle number density was smaller on the side than that in the middle because the laser intensity on both sides was weaker, and the corresponding sand particle information captured by PIV was reduced.
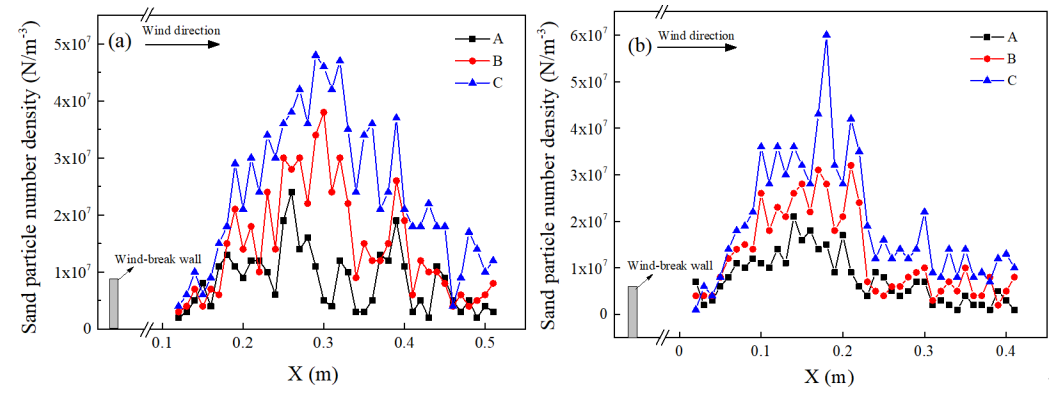

Figure 10. Number density of sand particles $\left(u_{*}=0.9701 \mathrm{~m} / \mathrm{s}\right)$. (a) $\mathrm{H}=0.05 \mathrm{~m}$ (above the track). (b) $\mathrm{H}=0.10 \mathrm{~m}$ (above the track).

As shown in Figure 11, the horizontal sand flux in case $\mathrm{C}$ on the railway track was the largest, that in case A was the smallest, and that in case B was between the two. 
The horizontal sand flux at different heights showed a wave-like change. At the height of $0.05 \mathrm{~m}$, the maximum horizontal sand flux in cases of A, B, and C all appeared at $0.39 \mathrm{~m}$ along the $\mathrm{x}$-direction. The horizontal sand flux in case $\mathrm{C}$ was the largest, and those in cases of $\mathrm{A}$ and $\mathrm{B}$ were lower by $70 \%$ and $47 \%$, respectively, than that in case $\mathrm{C}$. At the height of $0.10 \mathrm{~m}$, the horizontal sand flux in cases of A and B were lower by $76 \%$ and $52 \%$, respectively, than that in case $\mathrm{C}$.
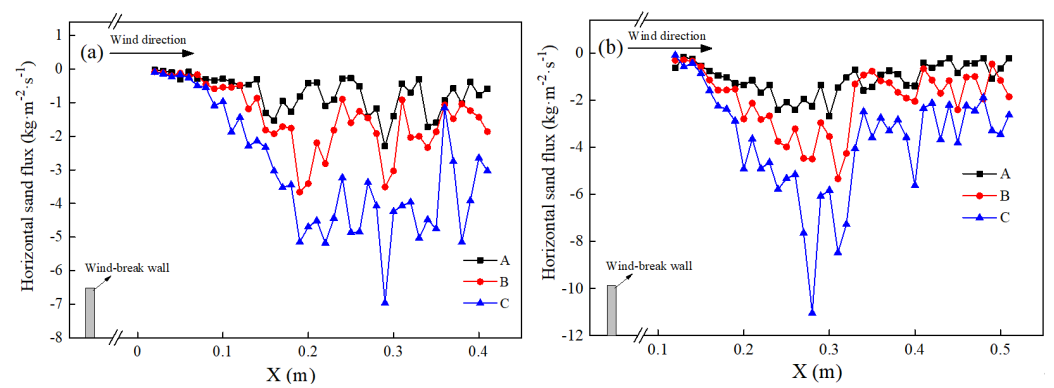

Figure 11. Horizontal sand flux ( $\left.u_{*}=0.9701 \mathrm{~m} / \mathrm{s}\right)$. (a) $\mathrm{H}=0.05 \mathrm{~m}$ (above the track). (b) $\mathrm{H}=0.10 \mathrm{~m}$ (above the track).

\subsection{Sand Particle Deposition Rate on Railway Track}

As shown in Figure 12a, the sand particle deposition rate of I was the highest. On the whole railway track, the sand particle deposition rate in case $C$ was higher by $89 \%$ and $87 \%$ than those in cases of $\mathrm{A}$ and B subgrades, indicating that the sand sedimentation in case $C$ on the railway track was the largest. Figure $11 \mathrm{~b}$ shows the total sand particle deposition rate on the leeward side of three wind-break walls at different wind speeds. As the incoming wind speed was increased, the total sand particle deposition rate was gradually increased, and the increase rate in case $C$ was higher.
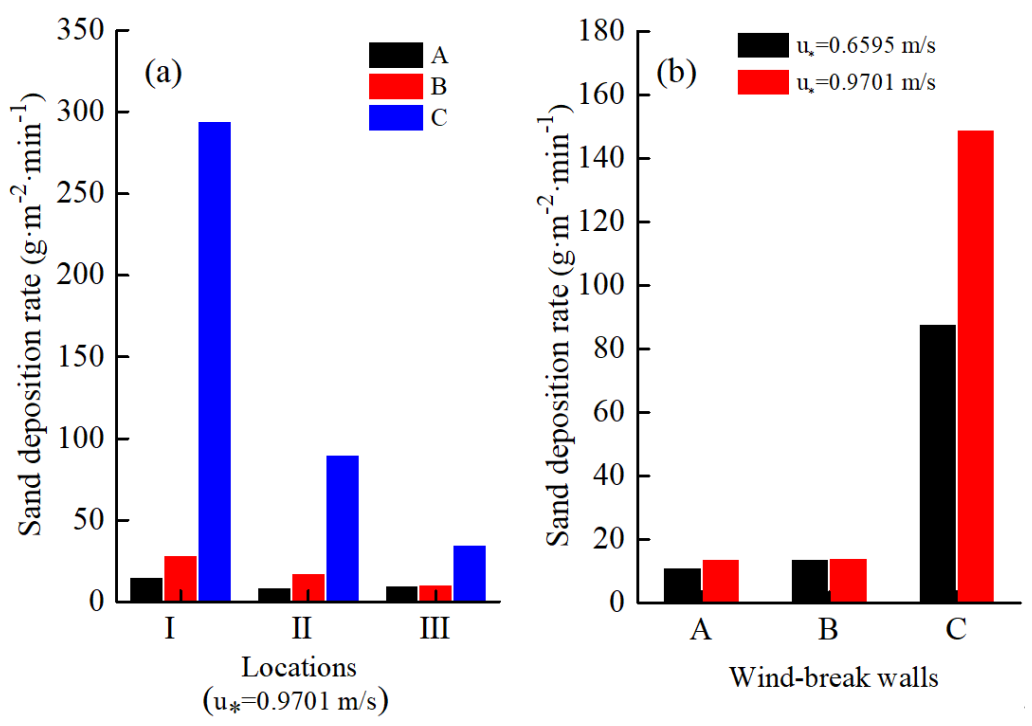

Figure 12. Sand particle deposition rates along three wind-break walls: (a) deposition rates at different locations and $(\mathbf{b})$ total deposition rates at different wind speeds.

Figure 13 shows the sand particle distribution on the leeward sides of three windbreak walls, and the wind direction is shown with arrows. The results show that the final sand particle distribution was consistent with all obtained results. 

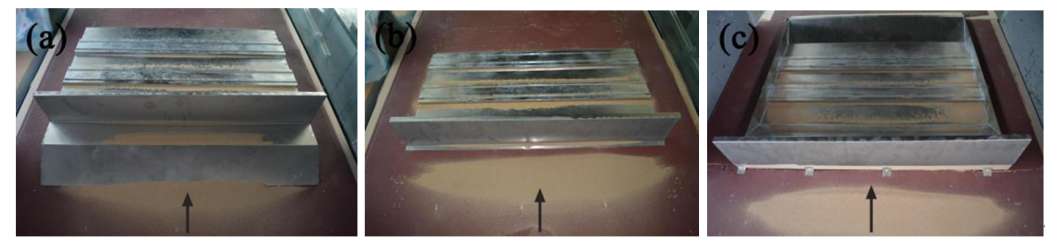

Figure 13. Sand particle sedimentation on the leeward sides of three wind-break walls: (a) convex subgrade, (b) flat subgrade, and (c) concave subgrade.

\section{Discussion}

In this study, the results show that sand sedimentation on the railway track of the concave subgrade was the most serious, and was about 10.7 and 4.4 times $\left(u_{*}=0.9701 \mathrm{~m} / \mathrm{s}\right)$ that of convex and flat subgrade. However, the tall length of concave wind-break wall was shorter than that of convex wind-break wall that was most of the $462.4 \mathrm{~km}$ wind zone railway of Lanxin Railway II. Therefore, in order to balance the influence of sand sedimentation on the whole railway track, it was necessary to take measures to reduce sand sedimentation along convex wind-break walls with the longest mileage and concave wind-break walls with serious sand sedimentation harm.

According to the flow field and sand sedimentation, some of the sand particles were carried back to the subgrade due to the existence of the backflow vortex. Therefore, in addition to setting up sand-fixing and sand-fence measures on the windward side of wind-break walls, it might be an effective measure to optimize the structure of wind-break walls or set up corresponding measures in the leeward backflow areas to reduce the sand deposition caused by backflow.

Along convex and flat wind-break walls, a second retaining wall at the top of slope P2 could be added in order to block the backflow of sand particles and make sand deposit behind the second retaining wall (Figure 14a,b). Because the distance between the windbreak walls and railway track is long $(8.5 \mathrm{~m})$ along concave wind-break walls, an inclined board could be set at a certain angle with the wind direction on top of the existing windbreak wall to make the original backflow area move backwards. A second retaining wall could then be added on top of slope P4 (Figure 14c). However, the inclined board could not be applied to convex and flat wind-break walls because the distance between the wind-break wall and railway track was short $(4.5 \mathrm{~m})$, and it would affect the overhead catenary system and other power supplying equipment of the high-speed train, such as the overhead contact line and cantilever structures $[8,9]$.

Through this study, the distribution laws of flow field and sand sedimentation on the leeward sides of three wind-break walls under different terrains were established, and some preliminary protective measures were accordingly proposed. Further studies on protective measures of wind-break walls within different terrains, such as the angle of the inclined board and the physical parameters of the second retaining wall, are continued and will be reported in the near future. 

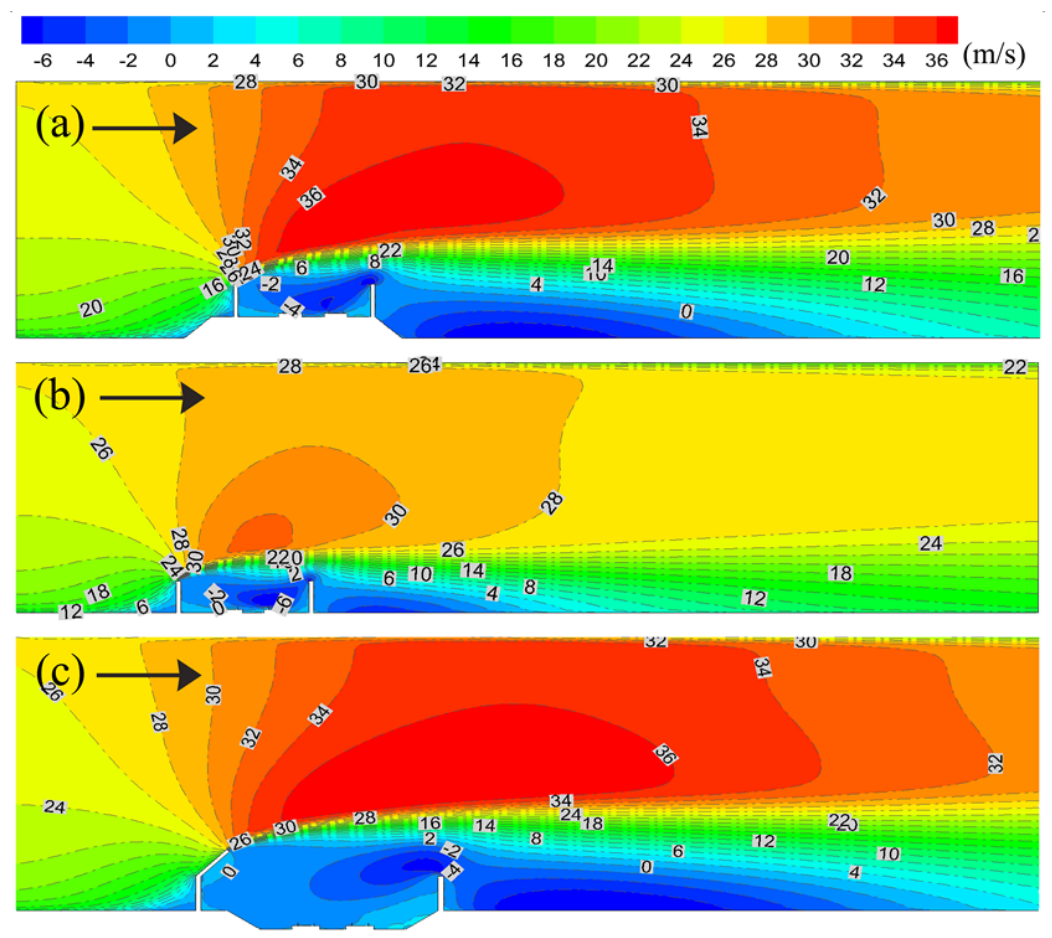

Figure 14. Sand sedimentation prevention measures along wind-break walls: (a) convex subgrade, (b) flat subgrade, and (c) concave subgrade.

\section{Conclusions}

In this study, three wind-break walls in different terrains, including convex, flat, and concave, were examined in a wind tunnel to determine the flow field, sand particle horizontal velocity, number density, sand flux, and deposition rate on the railway track.

The results show that the horizontal wind speeds along the three wind-break walls were first decreased and then increased with $x$ distance at different heights, and the peak wind speed of concave subgrade was much lower than those of convex and flat subgrades. The horizontal speed of sand particles was first increased and then decreased with $x$ distance on the leeward side at heights of 0.05 and $0.10 \mathrm{~m}$. The number density and horizontal sand flux along three wind-break walls showed that they were the largest in concave subgrade and the smallest in convex subgrade, with that in the flat terrain being between these two, indicating that the sand sedimentation of concave subgrade on railway tracks was the largest, which could be additionally confirmed with the sand deposition rate.

Meanwhile, some preliminary sand sedimentation prevention measures along the three wind-break walls were suggested according to the experimental results. Although these measures did not change the structure of existing wind-break walls and facilitate construction, they could effectively reduce the sand sedimentation on railway tracks and ensure the operation safety of high-speed trains in the strong wind area.

Not limited to wind-tunnel experiments and numerical simulations, more real-size field experiments should be carried out to verify theoretical assumptions in the future. Sand sedimentation caused by strong wind is widely distributed around the globe, and our research methods and results can be extended to highway and civil construction regions to resist sand sedimentation.

Author Contributions: Conceptualization, H.D. and G.X.; methodology, G.X.; software, G.X.; validation, J.Z.; formal analysis, H.D.; investigation, G.S.; resources, N.H.; data curation, G.X.; writingoriginal draft preparation, G.X.; writing—review and editing, H.D. and J.Z.; supervision, G.S.; project administration, N.H.; funding acquisition, N.H. All authors have read and agreed to the published version of the manuscript. 
Funding: This research was funded by the State Key Program of National Natural Science Foundation of China OF FUNDER grant number 41,931,179, the National Natural Foundation of China OF FUNDER grant number 11,772,143 and 11,702,163, and the Fundamental Research Funds for the Central Universities OF FUNDER grant number lzujbky-2021-pd09 and lzujbky-2020-cd06.

Institutional Review Board Statement: This study did not involve humans or animals.

Informed Consent Statement: This study did not involve humans.

Data Availability Statement: This study did not report any data.

Conflicts of Interest: The authors declare no conflicts of interest.

\section{Appendix A}

This study was mainly focused on the wind-break wall rather than the sand fence, because the sand fence was mainly used to reduce the sand particles from passing through the railway line and control the sand accumulation in the leeward sand-fixing barriers. As shown in Figure A1a-g, the sand fence with a porosity of about $30-60 \%$ and a height of about 1.5-2.0 m was set at about 100-150 $\mathrm{m}$ away from the railway line on the windward side.

However, the wind-break wall was mainly used to prevent damage to trains from strong winds. As shown in Figure A1h and Figure 1, the wind-break wall with no holes, but with a height of about 3.5-4.3 m, was generally set at 4-5 $\mathrm{m}$ away from the railway tracks. Initially, the wind-break wall was not believed to cause the sand particles to accumulate on the railway tracks. After the construction, it was found that the wind-break wall could reduce the speed of sand particles and cause sand particles to accumulate on the railway tracks (Figure A1c,d). The deposited sand particles would seriously affect the wheels, bogies, and electric motors of high-speed trains.

Up to the present, there have been a large number of reports on sand fences, but studies on sand accumulation caused by wind-break walls and the corresponding prevention measures are rarely reported.

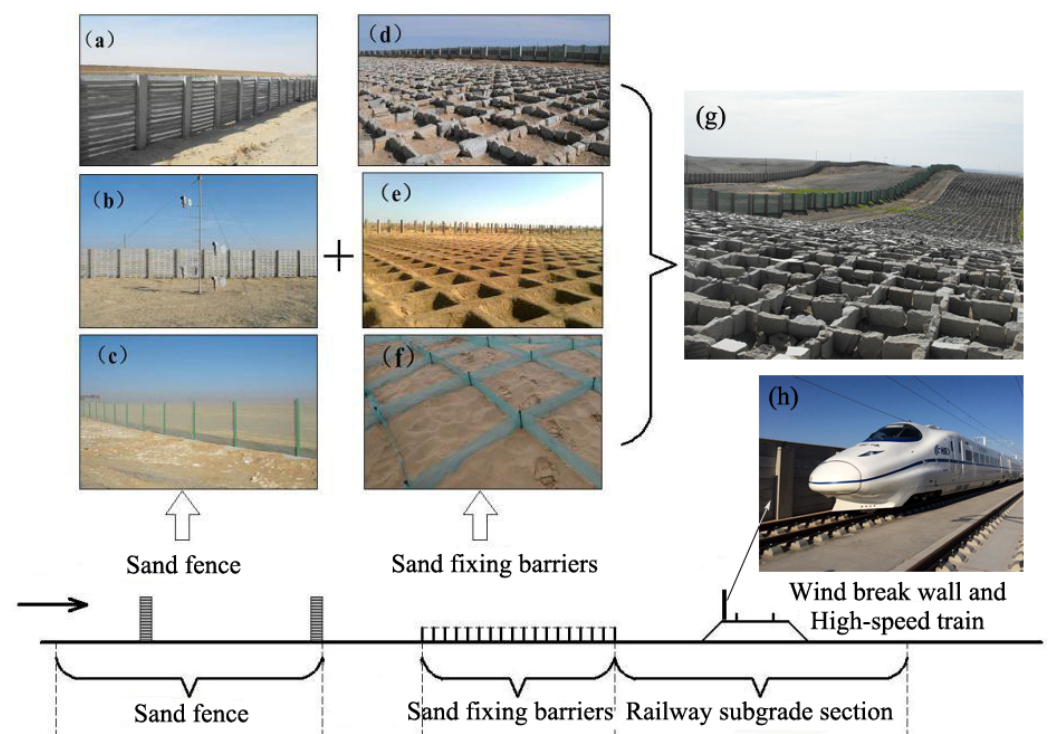

Figure A1. (a-c) Sand fences, (d-g) sand-fixing barriers, and (h) wind-break walls.

\section{References}

1. Zhang, J.; Wang, Y.; Jiang, F. Numerical Analysis on the Features of Sand Flow Movement around the Embankment of Lan-Xin Railway in Gobi Region. China Railw. Sci. 2011, 32, 14-18.

2. Cheng, J.J.; Lei, J.Q.; Li, S.Y.; Wang, H.F. Disturbance of the inclined inserting-type sand fence to wind-sand flow fields and its sand control characteristics. Aeolian Res. 2016, 21, 139-150. [CrossRef] 
3. Wang, T.; Qu, J.; Ling, Y.; Liu, B.; Xiao, J. Shelter effect efficacy of sand fences: A comparison of systems in a wind tunnel. Aeolian Res. 2018, 30, 32-40. [CrossRef]

4. Cheng, J.J.; Lei, J.Q.; Li, S.Y.; Wang, H.F. Effect of hanging-type sand fence on characteristics of wind-sand flow fields. Wind. Struct. Int. J. 2016, 22, 555-571. [CrossRef]

5. He, Y.W. Design of the Wind-resistant Gallery in Lanzhou-Xinjiang High Speed Railway. J. Railw. Eng. Soc. 2017, 34, 55-59.

6. Cheng, J.J.; Jiang, F.Q.; Xue, C.X.; Xin, G.W.; Li, K.C.; Yang, Y.H. Characteristics of the disastrous wind-sand environment along railways in the Gobi area of Xinjiang, China. Atmos. Environ. 2015, 102, 344-354. [CrossRef]

7. Xiao, J.; Yao, Z.; Qu, J.; Jiang, F. Characteristics and formation mechanism of extreme wind in hundred-li wind zone along Lanxin Railway. China Railw. Sci. 2016, 37, 130-137.

8. Rechena, D.; Infante, V.; Sousa, L.; Baptista, R. Design and failure modes of a standard railway catenary cantilever support. Eng. Fail. Anal. 2019, 107, 104217. [CrossRef]

9. Yang, S.A.; Zw, B.; Zl, C.; Rw, D. A spatial coupling model to study dynamic performance of pantograph-catenary with vehicle-track excitation. Mech. Syst. Signal Process. 2021, 151, 107336.

10. Pan, X.; Xiuqing, M.A.; Jie, X.U. Analysis and Evaluation About Anti-wind Efficiency of Windbreak Experimental Section in Lan-Xin High Railway. J. Arid Meteorol. 2019, 37, 496-499.

11. Qu, J.J.; Huang, N.; Lei, J.Q.; Dong, Z.B.; Liu, X.W.; Xue, X.; Zu, R.P.; Zhang, K.C. Structural characteristics of Gobi sand-drift and its significance. Adv. Earth Ences 2005, 20, 19-23.

12. Li, J.; Kandakji, T.; Lee, J.A.; Tatarko, J.; Collins, J.D. Blowing dust and highway safety in the southwestern United States: Characteristics of dust emission "hotspots" and management implications. Sci. Total Environ. 2018, 621, 1023-1032. [CrossRef] [PubMed]

13. Tian, Y.; Wang, Z.; Pan, X.; Li, J.; Wang, Z. Influence of the morphological change in natural Asian dust during transport: A modeling study for a typical dust event over northern China. Sci. Total Environ. 2020, 739, 139791. [CrossRef] [PubMed]

14. Zhou, D.; Yuan, X.X.; Yang, M.Z.; Xu, L.Z.; Zhang, L. Research on the anti-wind/sand effect of windbreak wall on high-speed train. J. Exp. Fluid Mech. 2012, 26, 63-67.

15. Huang, N.; Gong, K.; Xu, B.; Zhao, J.; Xin, G. Investigations into the law of sand particle accumulation over railway subgrade with wind-break wall. Eur. Phys. J. E 2019, 42, 145. [CrossRef]

16. Cheng, J.J.; Xin, G.W.; Zhi, L.Y.; Jiang, F.Q. Unloading Characteristics of Sand-drift in Wind-shallow Areas along Railway and the Effect of Sand Removal by Force of Wind. Sci. Rep. 2017, 7, 41462. [CrossRef] [PubMed]

17. Yan, Y.X.; Yan, X. Origin Analysis on Farmers' Housing Environment Adaptability Research in the Northwest Settlement of Dry Oasis Edge. Appl. Mech. Mater. 2012, 209-211, 248-251. [CrossRef]

18. Zeng, Q.L.; Zhen-Shan, L.I.; Fu-An, L.U.; Wang, Y.L. A Computational Study of Wind-break Performance of Ventilated Wind-break Wall in Different Locations on the Highway. J. Desert Res. 2012, 32, 1542-1550.

19. Lu, B.; Shen, A.Q.; Wei, Z.X.; Highway, S.O.; University, C. Comparison of In-situ Observation Effect of Highway Windbreak Structures and Simulation of Installation Optimization. J. Highw. Transp. Res. Dev. 2016, 33, 39-45.

20. Xiaohui, L.U.; Huang, N.; Ding, T. Wind tunnel experiments on natural snow drift. Sci. China Technol. Sci. 2012, 55, 927-938.

21. Sun, W.; Huang, N.; He, W. Turbulence burst over four micro-topographies in the wind tunnel. CATENA 2017, 4, 017. [CrossRef]

22. Tetsuya, K.; Yamagishi, Y.; Kimura, S.; Sato, K. Aerodynamic Behavior of Snowflakes on an Uneven Road Surface during a Snowstorm. Open J. Fluid Dyn. 2017, 7, 696-708. [CrossRef]

23. Xie, S.; Qu, J.; Han, Q.; Pang, Y. Wind Dynamic Environment and Wind Tunnel Simulation Experiment of Bridge Sand Damage in Xierong Section of Lhasa-Linzhi Railway. Sustainability 2020, 12, 5689. [CrossRef]

24. Dong, Z.; Qinan, G.; Lu, P.; Luo, W.; Wang, H. Turbulence fields in the lee of two-dimensional transverse dunes simulated in a wind tunnel. Earth Surf. Process. Landf. 2010, 34, 204-216. [CrossRef]

25. White, B.R. Laboratory Simulation of Aeolian Sand Transport and Physical Modeling of Flow Around Dunes. Ann. Arid Zone 1996, 35, 187-213.

26. Musick, H.B.; Trujillo, S.M.; Truman, C.R. Wind-Tunnel Modelling of the Influence of Vegetation Structure On Saltation Threshold. Earth Surf. Process. Landf. 2015, 21, 589-605. [CrossRef]

27. Yan, Y.; Shao, Y. Numerical simulations of flow and pollution dispersion in urban atmospheric boundary layers. Environ. Model. Softw. 2008, 23, 906-921.

28. Shi, F.; Huang, N. Computational simulations of blown sand fluxes over the surfaces of complex microtopography. Environ. Model. Softw. 2010, 25, 362-367.

29. Liu, S.; Pan, W.; Zhao, X.; Zhang, H.; Cheng, X.; Long, Z.; Chena, Q. Influence of surrounding buildings on wind flow around a building predicted by CFD simulations. Build. Environ. 2018, 140, 1-10. [CrossRef]

30. Wang, D.; Wang, Y.; Yang, B. An Algorithm in PIV Measurement of wind-sand two-phase flow. Chin. J. Theor. Appl. Mech. 2006, 3, 302-308.

31. Sun, W.; Huang, N. A study on velocity of aeolian sand particles over leeward slope by particle image velocimetry. Geomorphology 2018, 317, 157-169. [CrossRef] 
32. Zhang, Y.; Wang, Y.; Yang, B.; Jia, P. Measurement of sand creep on a flat sand bed using a high-speed digital camera: Mesoscopic features of creeping grains. Sedimentology 2015, 63, 629-644. [CrossRef]

33. Kang, L.; Zhang, J.; Zou, X.; Zhang, C.; Hong, C. Characteristics of Sand Transport during Initiation Process of Aeolian Sand Transport. J. Desert Res. 2017, 37, 1051-1058. 